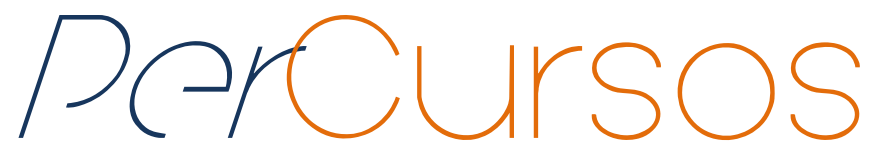

\title{
Periodismo, género y estatus de lo cultural: nuevas formas de sociabilidad em La Argentina (1962-1969)
}

\begin{abstract}
Resumo
Los años sesenta significaron transformaciones en las costumbres, las formas de socialización y las relaciones entre varones y mujeres. En la Argentina, estos cambios han sido asociados a los sectores medios. Ellos son concebidos a la vanguardia de un proceso de cambio que se habría expandido en las décadas siguientes a otros estratos sociales. Esta visión requiere ser discutida y complejizada porque implica una conexión lineal entre clase social y cambio cultural. Con esta ponencia no se pretende discutir el conjunto de este problema pero sí avanzar en esa dirección. Se propone que las innovaciones culturales en la sociabilidad y en el trato entre varones y mujeres fueron concebidas por los actores comprometidos con la modernización cultural como un símbolo de estatus social que colaboraba con la redefinición de los lugares en la pirámide social. En concreto, mostraremos cómo las revistas Claudia, Primera Plana, Adán y Satiricón, protagonistas de la renovación periodística, asociaron la apertura a las innovaciones con las actitudes de vanguardia y en esa operación construyeron una nueva élite social.
\end{abstract}

Palavras-chave: Journalism. Gender. Cultural Status: new socializing manners in Argentina (1962-1969).

\author{
Isabella Cosse \\ CONICET / Universidad de Buenos \\ Aires \\ Isabella.cosse@gmail.com
}

\section{Para citar este artigo:}

COSSE, Isabella. Periodismo, gênero y estatus de ló cultural: nuevas formas de sociabilidad em La Argentina (1962-1969). Revista PerCursos, Florianópolis, v. 14, n.27. jul./dez. 2013. p. 221 241.

DOI: $10.5965 / 1984724614272013221$

http: //dx.doi.org/10.5965/1984724614272013221 


\title{
Journalism, gender and cultural status: new socializing manners in Argentina (1962-1969)
}

\begin{abstract}
The sixties broad about changes in cultural patterns, socializing manners and relationships between men and women. In Argentina, these changes have been related to the middle class, wich was conceived as avant garde of the cultural modernization spread later to other social classes. This interpretation should be discussed as it implies a lineal connection between social class and cultural change. This paper does not intend to resolve the hold problem but to advance in this sense. I propose that cultural innovation in socializing and the relationship between men and women were conceived by the actors committed with the cultural modernization as a symbol of social status and a way to change the position in the social hierarchies. Summing up, I am going to explain the way magazines such as Claudia, Primera Plana and Adan -crucial actors in the journalistic renewal- connected the opening of social innovation with the avant garde attitude giving birth in this way to a new social elite.
\end{abstract}

Keywords: Journalism. Gender. Cultural Status.

Socializing. Argentina (1962-1969). 


\section{Introducción}

Los años sesenta significaron cambios en la moral, las costumbres y la sociabilidad que han sido concebidos como una revolución cultural (HOBSBAWM, 1995). Los estudios para América Latina han señalado que en la región esos procesos fueron atravesados por las profundas diferencias sociales, culturales y étnicas que atraviesan a las sociedades latinoamericanas. En este contexto, los cambios culturales de los años sesenta habrían interpelado especialmente a los jóvenes universitarios y contraculturales (ZOLOV, 1999; FRAZIER, COHEN, 2003; LANGLAND, 2006)

Las investigaciones pioneras para la Argentina propusieron que las transformaciones de los años sesenta surgieron de la confluencia de un campo cultural vigoroso y un público consumidor en expansión asociado con los nuevos segmentos medios, caracterizados por una mayor escolarización, capacidad adquisitiva y tiempo libre para el ocio cultural (AGUILAR, 1999; VARELA, 2005). Esto habría permitido el éxito de revistas como Primera Plana que asumieron la tarea de moldear las ideas y los estilos de vida de sus lectores y se posicionaron para ello como la mediación del capital simbólico entre lo nuevo y lo viejo, lo nacional y lo internacional (PUJOL, 2002, p.82-88; MAZZEl, 1997; PLOTKIN, 2003, 183-191).

La efervescencia cultural coincidió con una etapa de avance del autoritarismo en un clima crecientemente represivo y moralista profundizado con el golpe de Estado del general Juan Carlos Onganía en 1966, durante el cual a la prohibición del peronismo se le sumaron las otras fuerzas políticas, se intervinieron las universidades y se censuraron las más variadas manifestaciones culturales. La profundización de la censura fue un ejemplo del andamiaje represivo y del peso de la ideología tradicionalista e integrista en el gobierno que intentó frenar la difusión de valores y costumbres que, desde su óptica, representaban los valores materialistas y anticristianos que asediaban a Occidente desde siglos atrás (TERÁN, 1991; AVELLANEDA, 1986).

En este marco, investigaciones recientes han profundizado en la compleja relación entre los cambios culturales y las clases sociales, ofreciendo insumos para repensar la idea de que las clases medias habrían liderado las transformaciones. Por un lado, se ha planteado que la nueva sensibilidad urbana forjada en los años sesenta fue un resultado 
de los intentos de la clase media por establecer una hegemonía basándose en un proyecto modernizador que operó paradigmáticamente en el plano cultural (PODALSKY, 2004). Por otro, se ha descubierto que las transformaciones culturales no sólo se articularon con la identidad de clase media y que ésta estuvo también asociada al polo tradicionalista que se opuso a ellas (COSSE, 2010; MANZANO, 2009). En ese sentido, se ha insistido que el clima represivo no sólo caracterizó a la dictadura del general Onganía y tampoco emanaba exclusivamente del Estado que tenía antecedentes en el gobierno democrático de Arturo Frondizi (1958-1962) y que estuvo habilitado por una opinión pública moralista y por numerosas organizaciones católicas (MANZANO, 2005). Desde este ángulo, la modernización de las costumbres había escindido a la sociedad argentina de la época.

Estos resultados exigen profundizar en la pluralidad de experiencias y significaciones que tenía la clase media en la época y cómo ellas se engarzaron con los cambios culturales. Por un lado, ellos resaltaban el papel de la experiencia social de los individuos entre la cual asumen importancia aspectos como el lugar de residencia, el consumo, las formas de asociación y las preferencias culturales, en tanto parte de los elementos que contribuyen a la formación de la identidad. ${ }^{1}$ Por otro lado, en una dirección similar, con el giro culturalista se puso de relieve el papel de la ideología, las representaciones y las imágenes en la formación de la clase media, subrayando que ésta es el resultado contingente y dinámico de un proceso cultural e histórico. Estas líneas han sido revaluadas reciamente por las actuales investigaciones sobre la clase media en Argentina (PARKER, 1998; FURBANK, 2005; ADAMOVSKY, 2009; VISACOVSKY, GARGUIN, 2009). Desde este ángulo aquí retomamos la pregunta lanzada por Pierre Bourdieu sobre la formación de los criterios de distinción social, conectándola con los estudios que en las últimas tres décadas han renovado el análisis de la clase media (BOURDIEU, 1998).

Desde estos presupuestos, en estas páginas nos preguntamos cómo el nuevo periodismo hizo de las nuevas formas de sociabilidad un símbolo de estatus social que colaboraba con la redefinición de los lugares en la pirámide social. En concreto, plantearemos cómo las revistas Claudia, Primera Plana, Adán y Confirmado, que

\footnotetext{
${ }^{1}$ De este modo se retoman presupuestos de E. P. Thompson para el estudio de la clase obrera. Véase THOMPSON, (1995) y BLUMIN (1985).
} 
protagonizaron la renovación periodística, asociaron la apertura a las innovaciones con las actitudes de vanguardia y en esa operación construyeron una nueva élite social.

\section{Modernización cultural y renovación periodística}

En la Argentina de los años sesenta, la efervescencia cultural y la represión moralista componen una dupla que, como un oximoron, define las contradicciones de una época, entendida como un período con características únicas que lo distinguen del antes y del después. Para defensores y detractores, la modernización cultual era el signo de un tiempo de cambios concebidos irremediables. Eso habilitaba a imaginar la capital porteña como una urbe cosmopolita que vibraba con los ecos de las capitales del mundo. Esta imagen, claro está, no era una ingenua reproducción de la realidad pero revelaba una innegable apuesta a la apertura y al cambio cultural. ${ }^{2}$

En Buenos Aires, desde los años cincuenta, la recepción de la nouvelle vague había creado un círculo de cultores que se amplificó e hizo del gusto cinéfilo un símbolo de pertenencia a los círculos culturales que se imaginaban a la avanzada de los cambios. El mercado editorial también se renovó. Nuevas empresas y estrategias de distribución dirigidas al nuevo público lector, creado por la expansión de la matrícula secundaria y universitaria, hicieron posibles largas listas de best-seller, como los "boom" de la literatura latinoamericana pero también con catálogos que incluían el nuevo canon literario y las obras referenciales de las ciencias sociales y la psicología, que estaban en plena expansión. El mercado discográfico, al igual que en otros países latinoamericanos, articuló a escala trasnacional la conmoción creada por el rock que a las figuras internacionales sumó rápidamente las locales que, como los grupos Los Beatniks, Los Gatos y Almendra, dotaron de una vigorosa identidad a las culturas juveniles. Con diferente grado y características, los variados escenarios culturales fueron conmocionados por un clima de experimentación artística que logró ser acogida por un

\footnotetext{
${ }^{2}$ Esta definición se inspira en GILMAN (2003).
} 
público imaginado ávido y activo (SIGAL, 2002; GILMAN, 2003; PUJOL, 2003; MANZANO, 2009).

En este marco, el consumo cultural fue central en la delimitación de las fronteras porosas de la pirámide social y adquirió, por entonces, un carácter inédito. Pero esta clave no operó en forma aislada. Por el contrario, su importancia se redobló en el cruce de los cambios de la estructura social y de los cambios políticos.

Por un lado, desde el ángulo estructural, la sociedad argentina estaba atravesando fuertes transformaciones que habían reconfigurado las posiciones relativas en la pirámide social. Estaban aún presentes los impactos del crecimiento económico y las políticas de bienestar del peronismo, a lo que se sumaron los producidos por la política desarrollista del presidente Arturo Frondizi. La apertura a los capitales extranjeros, como vía para superar la dependencia y los problemas sociales, condujo al deterioro de las viejas industrias e impulsó el crecimiento de otras ramas y a la expansión de las áreas de comercialización y los servicios. Esto produjo cambios en la composición del empleo con el desempleo industrial y el crecimiento de los comerciantes cuentapropistas, de los empleados administrativos y del personal técnico y profesional (TORRADO, 1983).

Por otro lado, desde el ángulo político, los cambios culturales estuvieron marcados por el escenario de la caída del peronismo. Intelectuales, profesionales y artistas que habían sido desplazados en la década anterior se embarcaron en una refundación de la escena cultural con fuertes connotaciones políticas. En forma más o menos explícita esa renovación recolocaba en el centro a las clases medias, convertidas en un enigma que los intelectuales de izquierda y la sociología universitaria no terminaban de desentrañar y que desataba encendidas reacciones que iban desde el escarnio al optimismo con lo que era para muchos su propia clase. El problema implicaba elucidar su responsabilidad en la experiencia peronista pero, más importante aún, el papel que podía atribuírsele en el nuevo contexto. Rápidamente los fenómenos sociales, políticos y económicos por sí solos parecían no poder dar cuenta por completo del problema. De allí que los polémicos desacuerdos compartieran un nuevo interés por conectar esas dimensiones con las formas de vida, los valores y los rasgos mentales de las clases sociales (ALTAMIRANO, 2001). 
Esta común preocupación por desentrañar la conexión entre el estilo de vida y las posiciones políticas de la clase media partía de diferentes posiciones teóricas, diagnósticos y programas. El temprano interés de Gino Germani por las clases medias había estado unido a la comprensión del autoritarismo y ello lo había conducido a pensar en sus hábitos culturales. Inicialmente encaminada a entender las bases sociales del fascismo, esta preocupación cambiaría sólo unos años después, con el ascenso del peronismo. Este, concebido en línea con los totalitarismos europeos, exigía pensar cómo había sido posible que lograse el apoyo de la clase obrera y modificaba la interrogación por la clase media. Esta se insertaba en una interpretación de largo aliento sobre la sociedad argentina por la cual el país estaba atravesando una acelerada transición de la sociedad tradicional a la moderna en un proceso inconcluso marcado por fuertes contradicciones entre ambos polos (GERMANI, 1962, p. 253-266; 1987, p.41-63; BLANCO, 2006, p.143-145). En este proceso las clases medias podían tener un papel central al apuntalar la modernización cultural y, con ello, a la constitución de una sociedad democrática y estable.

En cambio, como ha planteado Carlos Altamirano desde la llamada "cultura de izquierda" las clases medias eran concebidas como la "pequeña burguesía" que, como había planteado la tradición marxista, era una clase oscilante, incapaz de encabezar un proceso revolucionario. Desde claves más concretas, este carácter las había colocado en temerosa oposición a la invasión plebeya del peronismo (ALTAMIRANO, 2001). Así, Juan José Sebreli explicaba que la incapacidad de la clase media para tener una posición colectiva la hacía evadirse de sus propios intereses y la hacían caracterizarse por el individualismo y la mezquindad. Esto explicaba su carácter de freno a la lucha de clases y su complicidad con la explotación de las clases sometidas. La necesidad de orden, notoriedad social y las pautas imitativas le otorgaban seguridad en un mundo que no controlaban y que sentían amenazante. Por eso, denunciaba su moral ("hipócrita”, “represiva”, “chata”, “mediocre”) que llevaba a la clase media a prestarse al "espionaje policial" de las cruzadas tradicionalistas que ocuparon crecientemente la escena cultural desde el mismo momento de la derrota del peronismo (SEBRELI, 1966, p. 63-79). 
Paradójicamente, estas visiones opuestas nutrieron un clima de época en el cual la modernización cultural congeniaba con la denostación de la moral instituida. La idea de que la sociedad argentina estaba atravesando profundas tensiones por la oposición entre la modernización y el tradicionalismo se volvió una especie de lugar común. Este podía retomar las imágenes demoledoras que plenas de ejemplificaciones impugnaban la moral de la ostentación y la hipocresía de la respetabilidad “pequeño burguesa”.

Ambos diagnósticos tenían una visión teleológica que facilitaban acordar -con diferentes intenciones y sentidos- que la sociedad argentina estaba desgarrada por la transición entre un pasado "tradicional” (“atrasado", “arcaico” o “patriarcal”) y un futuro concebido como "nuevo", "evolucionado", "avanzado". En esa dirección, el cambio cultural implicaba un estilo de vida que colaboraba en el sentido de esa dinámica histórica. El carácter irremediable de este proceso era potenciado con la clave generacional que colocaba a los jóvenes, por el sólo hecho de serlo, a la cabeza de dicho proceso. Esta interpretación se expandió y legitimó visiones, programas y proyectos inorgánicos y muchas veces contradictorios. Así, con las certezas dadas por la teoría y la versatilidad de las imágenes imprecisas, los impulsos modernizadores irradiaron a los más variados campos del quehacer nacional hasta fines de los años sesenta, cuando la radicalización política impuso otras oposiciones en la agenda.

Desde temprano, estos programas modernizadores se engarzaron con la renovación periodística. Desde fines de los años cuarenta, la Editorial Abril había sido la pionera en explorar la refundación de esa articulación, cuyas raíces se hundían en la marginación vivida por ciertas figuras intelectuales durante el peronismo, aunque su completa significación se expresó con posterioridad a su caída. Claudia, aparecida en 1957, constituyó la avanzada de la renovación. La revista reformuló las imágenes de la mujer moderna al distinguirla mediante el consumo, el gusto estético y la apertura cultural. El éxito fue inmediato. Con ventas de 120 mil ejemplares mensuales y nuevas estrategias de venta de publicidad, rápidamente se posicionó entre las líderes del mercado (BLANCO, 2006; COSSE, 2010, p.77-78). Un lustro después, en 1962, Primera Plana se impuso como el referente del nuevo periodístico. Su director, Jacobo Timerman, hizo de la provocación un estilo que identificó a la revista por los temas y la forma de tratarlos por los periodistas 
jóvenes y destacados que integraron la redacción. Ellos se dirigían a un público mayormente masculino formado por ejecutivos, profesionales y universitarios, concebido un lector activo, interesado en el estatus del consumo material y cultural, al que se gratificaba con la ilusión de pertenecer a un círculo elitista con opiniones propias al que los periodistas supuestamente sólo informaban, ocultando su misión educativa (CARTA..., 1963; PUJOL, 2002, p.82-88; PLOTKIN, 2003, p.183-191).

Ambas revistas instalaron una marca que, más allá de las diferencias, compartieron otros títulos emblemáticos de la renovación periodística, como Confirmado, Panorama y Análisis. Tenían en común el proponer un programa de modernización cultural, un estilo periodístico ágil, directo y provocador y un público que se identificaba con los sectores medios en ascenso. Compartieron, también, ciertas estrategias de comunicación. Por un lado, difundieron las novedades de Europa y Estados Unidos convirtiéndolas en medida de contraste para evaluar la realidad del país y en medios para instigar los debates locales. Por el otro, dieron forma a una elite local, en la cual se incluían el staff de las revistas, mediante la selección de los columnistas, los entrevistados y los reseñados, presentada como un polo dinámico de la modernización y prestigiada en términos del estatus sociocultural.

Desde ambas puntas, esas revistas propusieron un pacto de lectura que le prometía al lector la ilusión de pertenecer a "los altos estratos de la pequeña burguesía urbana de la Argentina" y con ello le ofrecía una vía para incorporarse a ese estilo de vida "actual", “moderno" y "adelantado" que demarcaba una posición ascendente en la pirámide social (LOS NUEVOS..., 1966). Es decir, esas revistas establecían una guía para la educación y el refinamiento de los gustos, las actitudes y las costumbres de quienes se aspiraba a que liderasen la modernización cultural y, al mismo tiempo, se creaba una élite que era ubicada a la avanzada de la misma.

De allí que el consumo de revistas les permitieran a diferentes nichos de lectores sentirse integrados -y también integrarse- a los nuevos estilos de vida que revelaban y exigían capacidades sociales, económicas y culturales que poseía sólo un segmento reducido de la población. Así, por ejemplo, no se necesitaba sólo dinero para pagar la entrada del cine para ver a Bergman, sino también capacidad para opinar sobre la película 
a la salida. Estas revistas colaboraban en ambas direcciones: moldeaban los gustos y permitían tener opinión. Claro que podía hacerse una cosa sin la otra. Las sospechas de que muchos compradores se paseaban con un título de Cortázar en el brazo sin haberlo leído revelan cómo los consumos culturales compusieron un marcador sensible del estatus sociocultural (CORTÁZAR..., 1968; PLOTKIN, 2003, p.183-191; COSSE, 2006a).

El proceso no era nuevo. Los conflictos por la delimitación de las fronteras móviles y porosas de la pirámide social contaban con largos antecedentes en un país que hizo del ascenso social una promesa abierta a diferentes estratos sociales. Esto significó un complejo y poderoso proceso de competencia y búsqueda de diferenciación que se expresó en forma paradigmática en el plano de los comportamientos familiares. De hecho, el modelo familiar fue uno de los escenarios donde se expresaron las pugnas por la respetabilidad social y mostraron todo su potencial conflictivo durante el peronismo, cuando se imantaron de tonalidades políticas. ${ }^{3}$ En los años sesenta esas pugnas fueron un parte aguas que marcó con especial fuerza la reconfiguración de la identidad sociocultural de los jóvenes. Como veremos, los estilos de sociabilidad fueron una dimensión central de este proceso.

\section{Una sociabilidad anticonvencional}

Me Ilamo Adriana Buteler, tengo 19 años, algunas entradas en la policía, dos ingresos a la facultad -Psicología y Ciencias Exactas-, un viaje por América haciendo dedo, dos amigos que me acompañaron entonces (...). Los hombres cuando intentan seducirme repiten fórmulas vacías carentes de originalidad, tácticas que, por lo elementales, resultan ofensivas (VIDA..., 1963; BUTELER, 1966)

Este párrafo, supuestamente, era parte de las "memorias informales" de una modelo de nuevo tipo que intentaba imponer la revista Adán en 1966. Delineaba la imagen de una joven contestataria y desinhibida para ofrecérsela como un objeto de deseo al público viril. Esta era una de las estrategias de un programa de refinamiento

\footnotetext{
${ }^{3}$ En relación a la importancia de estas dinámicas de diferenciación, véase. Adamovksy, 2009. En cuanto a su relación con la familia, véase Losada (2008) y Cosse (2006b).
} 
asumido por la nueva publicación de editorial Abril y llevado a cabo por periodistas como Luis E. González O’Donnell, H. Alsina Thevenet y Miguel Brascó (ULANOVSKY, 1995). La apuesta se dirigió, imitando a Playboy (EHRENREICH, 1983), a crear un modelo viril que combinaba hedonismo y apertura cultural, dirigido a profesionales, empleados y empresarios de las nuevas ramas de servicios crecida con las políticas desarrollistas. Así, bajo la consigna de que el dinero no bastaba para otorgar estatus, se apelaba a la navegación y caza, la comida sofisticada y la literatura (Miller, Bradbury y Onetti) para moldear la identidad de una nueva clase ejecutiva (GAZETA, 1966; ONETTI, 1967; MILLER, 1966).

El proyecto no tuvo éxito. La revista eclipsó a los dos años. En parte quizás porque otras propuestas interpelaron mejor al público al que se dirigía, en parte porque la ofensiva moralista del general Onganía no era el contexto más adecuado para una revista que establecía, casi como una declaración de principios, que había que combatir el moralismo sexual. Pero el ejemplo muestra el papel de la renovación periodística en la modernización cultural y cómo ésta se conectó con la redefinición de las jerarquías sociales y de la identidad de la clase media en el escenario de la derrota del peronismo. En este juego de espejos, los espacios de sociabilidad tenían un papel central.

En 1963, una de las primeras notas de Primera Plana en la sección "vida moderna" trazaba una cartografía de las jerarquías sociales a partir de la vida nocturna de la "clase alta" y la "clase media alta". Para que no quedaran dudas el precio del vaso de "scotch" era un barómetro de las diferencias. Entre las boîtes de nivel colocaba a Gong`s (anclada en la "clase alta”) y Zum-Zum (“moderadamente elegante”) y entre las menos exigentes situaba a Scandale y Bossa Nova, frecuentada por universitarios. Como podía leerse en Adán, estas boîtes eran concebidas como ámbitos de sofisticación abiertos a los “nouveau riche", que estaban "afinando sus gustos con una rapidez fabulosa”, según explicaba el dueño de Mau Mau, otra reconocida boîte en cuya pista podían cruzarse la modelo Chunchuna Villafañe, el escritor Rodolfo Walsh y Rafael Martínez de Hoz (MARTELLI, 1967).

Junto a estas descripciones figuraban las centradas en la bohemia local formada por distintos círculos sociales (intelectuales, artistas, psicoanalistas y hippies) que tenían 
un estatus privilegiado por su apertura cultural. Así, Primera Plana mostraba a Villa Gesell como un lugar exclusivo donde reinaba la distensión de las costumbres, donde los habitúes eran en su mayoría jóvenes “mochileros” que “odiaban la urbanización”, aunque también podían existir algunos matrimonios. Allí era un “insulto” andar con zapatos, estaban suprimidas las "hojitas" de afeitar y la vestimenta debía ser simple En modo semejante Panorama, la revista de actualidad de editorial Abril, explicaba que en la “manzana loca” (delineada por las calles Florida, Charcas, Paraguay y Esmeraldas) los jóvenes artistas del Di Tella y los estudiantes de la Facultad de Filosofía y Letras de la Universidad de Buenos Aires creaban un mundo exclusivo, habitado por un público “minifaldesco”, “barbado” y “descreído”. Con una descripción diferente, esta revista también reputaba el clima de la calle Corrientes, donde los bares (como el Politeama y La Paz) y las librerías eran centros de encuentro informal, en los que supuestamente podían encontrarse a integrantes de los Gatos o los Beatniks o los discípulos del reconocido psicoanalista Pichon Rivière (VILLA GESELL..., 1965; VIDA..., 1968; COSTUMBRES..., 1974).

Las revistas también ofrecieron ventanas para imaginar una sociabilidad más exclusiva de fiestas y eventos culturales. En 1966, Confirmado describía el ambiente glamoroso de los happening privados, a los que asistían sólo una decena de invitados como Graciela Borges, Clorindo Testa, Carlos Perciavalle pero también el abogado Luis Astigueta y el político Raúl Taborda, sumados a "industriales, aristócratas y criadores de caballos" no identificados. Después de las lentejas y el vino, se explicaba, los invitados debieron reptar por debajo de un gigantesco corset de yeso que comunicaba con un insecto colgante dentro del cual danzaban "frenéticamente" cuatro personajes “indescifrables", vestidos sólo con escasos "trapitos" (HAPPENINGS..., 1966). Como puede observase, se describía un círculo exclusivo en el que se entremezclaban personas pertenecientes a diferentes sectores sociales en función de su apertura a experimentar el arte de vanguardia y la sociabilidad distendida. De no tener acceso a estos círculos, el clima snob podía disfrutarse en La botica del Ángel, donde Eduardo Bergara Leumann abría su casa para crear una "atmósfera de fiesta colectiva" y favorecer una "especie de terapia" que lograba "sacarle el almidón a la gente, en un país de gente con almidón", 
como afirmaba Panorama en 1968 (PSICOTERAPIA..., 1968). En forma similar, la revista explicaba, por su parte, que entre los muchachos y muchachas de la clase media vinculados “de cerca o de lejos" a la actividad intelectual o artística a los que catalogaba de "bastante evolucionados", las fiestas (llamadas según explicaba con un término “impublicable”) se organizaban improvisadamente, se difundían de boca en boca y era posible asistir aunque se desconociera al dueño de casa. Expresamente se aclaraba que la procedencia social de esos jóvenes “evolucionados” podía ser muy distinta al igual que las inserciones culturales pero que los aunaba su pertenencia generacional. De este modo, la sociabilidad distendida denotaba la pertenencia a un grupo social que se definía por la pertenencia generacional, los espacios que ocupaban y la proximidad a los centros de los que emanaba la modernización cultural.

En contraposición, el rechazo de las innovaciones era presentado como una característica que identificaba a los sectores alejados de la vanguardia y en consonancia más bajos en la escala social. Así lo mostraba el análisis de Primera Plana sobre una encuesta sobre "el amor entre los argentinos", de 1963, eufemismo que refería a la sexualidad, que revelaba el peso que seguían teniendo las diferencias de género y los prejuicios sociales. Por ejemplo, según los resultados, los entrevistados de “clase media y baja" pensaban que la infidelidad de la mujer era "síntoma inequívoco de la impotencia del marido". Esta idea se acentuaba, supuestamente, entre los “niveles populares” como dejaba entrever un mecánico que había confesado: "si mi mujer tuviese relaciones con otro hombre -sin el menor asomo de sorna-, empezaría por golearla. Pero después iría al médico." La aclaración sobre la seriedad de la afirmación establecía la complicidad entre el periodista y los lectores y que creaba una distancia -simulada- entre su universo cultural y el de los encuestados (ENCUESTAS..., 1963). Esta distancia quedaba reforzada en la conclusión en la que el periodista asumía el rol del analista social que podía lamentarse de que prevaleciera la subestimación de la mujer pero que también observaba el avance de los cambios. Igual estrategia usaba Confirmado, en 1967, por ejemplo, en una reseña sobre la película Noche Terrible de Rodolfo Kuhn, al explicar que "Ios optimistas" que pensaran que las críticas del director a las represiones del "pequeño burgués porteño" eran antiguas estaban desconociendo que "la clase media porteña (sólo) ha 
cambiado su apariencia en algunos márgenes superiores" (ESPECTÁCULOS..., 1967). Estas interpretaciones mostraban que la clase media no era vista como un sector homogéneo y que existían muchas formas de pensar quiénes estaban a la vanguardia de los cambios.

Nuevamente, las descripciones de las élites locales permitían enlazar el estilo espontáneo de sociabilidad y de relaciones de pareja con el carácter generacional y social de las transformaciones culturales. Como explicaba a Adán, en 1967, la distensión dominaba la pista de Mau Mau, la vidriera social donde supuestamente se cruzaba la "nueva clase" con la vieja elite tradicional. Pero, en forma significativa, se resaltaba que en ese espacio la informalidad también asumía un carácter generacional. Identificaba a los menores de veinticinco años, al punto que hacían sentirse viejo al propietario de la boîte, Alberto Latta Liste que tenía treinta. Según él, los jóvenes habían dado un vuelco "total” a las relaciones entre varones y mujeres, dotándolas de mayor comunicación y sinceridad. De modo similar, funcionaban las descripciones de la sociabilidad de los círculos de artistas, plásticos y críticos de arte como mostraba la crónica de la III Bienal de Arte Americano, realizada en Córdoba, de Adán en 1966, donde los invitados eran connotados por su belleza, juventud y notoriedad social o cultural, donde se bromeaba sobre el clima distendido del evento al sostener que había dado lugar a mil quinientas personas entrando y saliendo de habitaciones que no eran la suya, trescientos quince "amores fugaces", cuarenta y dos parejas "dañadas por la sospecha" de infidelidad y siete matrimonios “destruidos por la venganza” (MARTELLI, 1967; SOCIALES..., 1966). Es decir, la rapidez para establecer vínculos era concebida como una innovación que dotaba de un glamour descontracturado a estos círculos prestigiados social y culturalmente.

Sumada a la valorización social, como adelantamos, esta nueva sociabilidad quedó engarzada con una percepción generacional. Esto se mostró en forma paradigmática en una encuesta, realizada por Análisis en 1969, a jóvenes de 15 a 25 años, entre quienes la espontaneidad era el aspecto más valorado, luego de la belleza. El rechazo a las formalidades significaba la intención de diferenciarse de los patrones de los mayores y estaba asociado con la mayor jerarquía social porque esta opinión era más frecuente entre la clase media y alta. Ellos aparecían como los círculos más abiertos a los cambios en 
las costumbres, según las opiniones transcriptas en la encuesta. Así, mientras una universitaria de 19 años valoraba la simpatía y la desenvoltura, y un abogado de 25 años la espontaneidad, un obrero de 16 años con estudios primarios interrumpidos deseaba que fuera "buena chica y que sepa respetar" y otra joven de igual nivel de instrucción quería que el chico no fuera “mano larga, que trabaje y que sea bueno". De igual modo podían leerse críticas a los adultos por su “terrible inhibición” (universitaria, 19 años), por sus actitudes "hipócritas” y porque para ellos el amor estaba "envasado" (universitario, 22 años) y era "poco natural” y "muy ceremonioso" (músico, 22 años) (CÓMO SE AMAN..., 1969). En función de estas opiniones, las críticas a las costumbres y la valoración de la espontaneidad quedaban asociadas con los jóvenes universitarios, artistas y profesionales. La imagen que abría la nota lo confirmaba. En ella se veía una pareja formada por un joven con jeans y medias a rayas y una chica sin maquillaje, con el pelo encrespado y camisola suelta apoltronada bajo una reproducción de Modigliani.

En 1971, un artículo de Panorama revelaba en forma prístina las connotaciones sociales de las nuevas formas de relaciones de pareja. El artículo estaba basado en un estudio con más de veinte mujeres y reproducía fragmentos de las entrevistas a cuatro de ellas, pertenecientes a diferentes estratos sociales. Ellas componían una cartografía social de los cambios en la regulación de los noviazgos por la cual las mujeres de más jerarquía social, que identificaban a la clase alta y clase media profesional, eran colocadas a la avanzada de la distensión de las costumbres y de la creación de estándares supuestamente subjetivos. Por el contrario, las de menor jerarquía, que se identificaba con la entrevistada que era empleada bancaria y con la verdulera, mantenían con variantes las fórmulas establecidas. Así, para la empleada bancaria el primer paso había sido que su compañero de trabajo la acompañara a la casa, quedándose ambos conversando fuera, seguido de la invitación de la madre a que entrara y, después, de la declaración amorosa, aceptada a condición de que se comprometiera formalmente. Para ello, el novio le pidió la mano al futuro suegro, manteniendo una conversación de “hombre a hombre", considerada una formalidad, aunque la prometida temblaba en la cocina. Luego de lo cual siguió un compromiso sencillo organizado por la novia en el cual intercambiaron los anillos. En cambio, la socióloga explicaba que había conocido a su 
futuro novio en su propia casa y que había sido ella la que lo había invitado a salir, no había recibido ninguna declaración, tampoco había existido compromiso formal ("no es importante, lo que vale es amarse") ni pedido de mano: sus padres se había enterado del casamiento una semana antes; y los suegros un mes después, cuando regresaron de Europa. De este modo, el análisis contenía una segmentación que mostraba la heterogeneidad de la clase media y colocaba a la vanguardia de los cambios a los círculos profesionales e intelectuales, mientras que los de empleados y trabajadores seguirían las pautas tradicionales (KOTZER, 1971).

\section{Conclusiones}

Las revistas del nuevo periodismo tuvieron no sólo un papel activo en los cambios culturales que caracterizaron a los años sesenta sino que, también, propusieron en forma simultánea una topografía social y una nueva elite que delineaban en función de la apertura a las transformaciones. En especial, los estilos de sociabilidad fueron centrales en esas estrategias que promovían la modernización cultural. Mediante notas, reseñas y encuestas, la naturalidad y la espontaneidad en las relaciones interpersonales eran asociadas con las pautas que dominaban en una nueva élite social.

Sin embargo, también hemos mostrado la existencia de ciertas ambigüedades para definir qué sectores estaban encabezando las transformaciones culturales y, por tanto, eran presentados como la avanzada de la nueva élite social. Más allá de ello, parecerían haber existido ciertos vasos comunicantes en esas percepciones. Por un lado, las transformaciones no quedaban asociadas con la clase media en su conjunto sino con círculos sociales específicos, que combinaban el estatus cultural y educativo como evidencian las referencias a los intelectuales, los artistas, los universitarios y los hippies. Por otro lado, parecería evidente, también, que esta definición en términos sociales era atravesada por la dimensión generacional por la cual los jóvenes estaban encabezando un proceso concebido en forma irremediable. En definitiva, los cambios en la sociabilidad fueron entendidos como un escenario central de la redefinición sociocultural de las 
nuevas generaciones que les permitieron distinguirse frente al mundo heredado de sus padres y redefinir su lugar en la pirámide social.

\section{Referências Bibliográficas}

ADAMOVSKY, Ezequiel. Historia de la Clase Media Argentina. Apogeo y Decadencia de una Ilusión, 1919-2003. Buenos Aires: Planeta, 2009.

AGUILAR, Gonzalo. Televisión y vida privada. In: DEVOTO, F.; MADERO, M. Historia de la vida privada en la Argentina. La Argentina entre soledades y multitudes. De los años treinta a la actualidad, Buenos Aires: Santillana, 1999. p. 255-283. Tomo 3.

ALTAMIRANO, Carlos. Peronismo y cultura de izquierda. Buenos Aires: Tema Grupo Editorial, 2001.

ARCHIVO DE LA DIRECCIÓN DE CONTRALOR DE PUBLICACIONES, Estadísticas de publicaciones.

AVELLANEDA, Andrés. Censura, autoritarismo y cultura: Argentina 1960-1983/1.Buenos Aires: CEDAL, 1986.

BLANCO Alejandro. Razón y modernidad. Gino Germani y la sociología en la Argentina. Buenos Aires: Siglo XXI, 2006.

BLUMIN, Stuart M. The Hypothesis of Middle Class Formation in Nineteenth-Century America: a Critique and Some Proposals. American Historical Review, v. 90, p. 299-339, Apr. 1985.

BOURDIEU, Pierre. La distinción. Criterio y bases sociales del gusto. Madrid: Taurus, 1998.

BUTELER, Adriana. Memorias informales. Adán, n. 4, p. 60-64, oct. , 1966.

CARTA al lector. Primera Plana, n. 53, p. 3, 12 de nov., 1963.

CORTÁZAR: un invento productivo. Confirmado, n. 178, p. 10-1214, nov. ,1968.

COSSE, Isabella. Familia, pareja y sexualidad en los años sesenta. Buenos Aires: Siglo XXI, 2010.

. Cultura y sexualidad en la Argentina de los 60`: usos y resignificaciones de la 
experiencia trasnacional. Estudios interdisciplinarios de América Latina y el Caribe, v. 17, n. 1, p.39-60, enero-jun. 2006a.

. Estigmas de nacimiento. Peronismo y orden familiar (1946-1955). Buenos Aires: Fondo de Cultura Económica, 2006b.

CÓMO SE AMAN los jóvenes. Análisis, n. 422, p. 40-46, 15 al 31 de abr., 1969.

COSTUMBRES en el Village. Panorama, n. 382, p. 34-35, 29 de oct. , 1974.

EHRENREICH, Barbara. The Hearts of Men: American Dreams and the Flight from Commitment. New York: Doubleday, 1983.

ENCUESTAS. El hombre argentino cree en el amor, pero subestima a su pareja. Primera Plana, n. 43, p. 20-253, sept., 1963.

ESPECTÁCULOS. Una noche para Roberto Arlt. Confirmado, n. 116, p. 54-55, 7 de sept. de 1967.

FRAZIER, Lessie Jo.; COHEN, Deborah. Defining the Space of Mexico `68. Heroic Masculinity in the Prison and 'Women ' in the Street. Hispanic American Historical Review, v. 83, n. 4 , p. 617-620, 2003.

FURBANK, Philip. Un placer inconfesable o la idea de clase social. Buenos Aires: Paidós, 2005.

GAZETA. Adán, Año 1, n. 5, p. 3-5, nov., 1966.

GERMANI, Gino. Política y sociedad en una época de transición. De la sociedad tradicional a la sociedad de masas. Buenos Aires: Editorial Paidós, 1962.

. Estructura social de la Argentina. Análisis estadístico, [1955]. Buenos Aires: Solar, 1987.

GILMAN, C. Entre la pluma y el fusil. Debates y dilemas del escritor revolucionario en América Latina. Buenos Aires: Siglo XXI, 2003.

HAPPENINGS. Qué los parta un rayo.Confirmado, n. 59, , p. 39-40, 4 de ago. 1966.

HOBSBAWM, Eric. Historia del Siglo Veinte. Barcelona: Crítica, 1995.

KOTZER, Kado. Testimonios. Transfiguración del pedido de mano. Panorama, n. 199, p. 42- 
44, 16 de feb., 1971.

LANGLAND, Victoria. Il est Interdit d'Interdire: The Trasnational Experience of 1968 in

Brazil. Estudios interdisciplinarios de América Latina y el Caribe, v. 17, n. 1, p. 61-81, enerojun. 2006.

LOSADA, Leandro, La alta sociedad en la Buenos Aires de la Belle Époque, Buenos Aires: Siglo Veintiuno, 2008.

LOS NUEVOS mandarines. Confirmado, 12 de mayo de 1966, p. 48-49.

MANZANO, Valeria. The Making of Youth in Argentina: Culture, Politics, and Sexuality (19561976). (Ph Dissertation) - Indiana University, Bloomington, 2009.

. Blue Jean Generation: Youth, Gender, and Sexuality in Buenos Aires (1958-1975).

Journal of Social History, p. 103-122, Spring 2009.

. Sexualizing Youth: Morality Campaigns and Representations of Youth in Early$\overline{1960 s}$ Buenos Aires. Journal of the History of Sexuality, v. 14, n. 4, p. 433-461, Oct. 2005.

MARTELLI, Juan Carlos. Testimonios. El hombre que inventó Mau Mau. Adán, Año 1, n. 7, p. 53-56, enero de 1967.

MAZZEI, Daniel H. Medios de comunicación y golpismo. El derrocamiento de Illia (1966). Buenos Aires: Grupo Editor Universitario, 1997.

MILLER, Henry. Literatura. Adán, n. 2, agosto de 1966,[ s/p].

ONETTI, Juan Carlos. Historia del caballero de la rosa y de la virgen encinta que vino de Liliput (con ilustraciones de Xul Solar). Adán, Año 1, n. 7, p. 99-105, enero de 1967.

PARKER, David Stuart. The Idea of the Middle Class: White-collar Workers and Peruvian Society, 1900-1950. Pennsylvania: Pennsylvania State University Press, 1998.

PLOTKIN, Mariano. Freud en las Pampas. Buenos Aires: Sudamericana, 2003.

PODALSKY, Laura. Specular City: Transforming culture, Consumption, and Space in Buenos Aires, 1955-1973. Philadelphia: Temple University Press, 2004.

PSICOTERAPIA del vino y del buen humor. Panorama, n. 64, p. 66, 16 de jul., 1968. 
PUJOL, Sergio. Rebeldes y modernos. Una cultura de los jóvenes. In: James, Daniel (Dir.). Nueva Historia Argentina. Violencia, proscripción y autoritarismo (1955-1976). Buenos Aires: Editorial Sudamericana, 2003. . La década rebelde. Los años sesenta en la Argentina. Buenos Aires: Emecé, 2002.

SEBRELI, Juan José. Buenos Aires, vida cotidiana y alienación. 9. ed. Buenos Aires: Siglo Veinte, 1966.

SIGAL, Silvia. Intelectuales y poder en la Argentina. La década del 60. Buenos Aires: Siglo XXI, 2002.

SOCIALES. Pert y erotismo. Adán, n. 5, p. 20-21, nov., 1966.

TERÁN, Oscar. Nuestros años sesenta. Buenos Aires: Puntosur, 1991.

THOMPSON, Edward P. Costumbres en común. Estudio de la cultura popular tradicional. Barcelona: Crítica, 1995.

TORRADO, Susana. Estructura Social en la Argentina (1945-1983). Buenos Aires: Ediciones de La Flor, 1983.

ULANOVSKY, Carlos. Días de radio. Historia de la radiofonía Argentina. Buenos Aires: Espasa Calpe, 1995.

VARELA, Mirta. La televisión criolla. Desde sus inicios hasta la llegada del hombre a la luna (1951-1969). Buenos Aires: Edhasa, 2005.

VIDA Nocturna: ¿Es que ya no quedan play-boys? Primera Plana, n. 31, p. 25, 11 de jun., 1963.

VIDA de hoy. Buenos Aires. La manzana loca. Panorama, n. 63, p. 32-34, 9 de jul., 1968.

VILLA Gesell. La leyenda de los raros. Primera Plana, n. 119, p. 28-29, 16 de feb. ,1965.

VISACOVSKY, Sergio; GARGUIN, Enrique (Comp.). Moralidades, economías e identidades de clase media. Buenos Aires: Ediciones Antropofagia, 2009.

ZOLOV, Eric. Refried Elvis: The Rise of the Mexican Counterculture. [California: USA] : University of California, 1999. 
Recebido em: 20/09/2013 Aprovado em: 24/11/2013

Universidade do Estado de Santa Catarina - UDESC Centro de Ciências Humanas e da Educação - FAED Revista PerCursos Volume 14 - Número 27 - Ano 2013 revistapercursos@gmail.com 